\title{
Voltammetric behavior and determination of the macrolide antibiotics azithromycin, clarithromycin and roxithromycin at a renewable silver - amalgam film electrode
}

\author{
Olga Vajdle ${ }^{a}$, Valéria Guzsvány ${ }^{a}, *$, Dušan Škorića ${ }^{a}$, János Csanádi ${ }^{a}$, Miloš Petkovićb \\ Milka Avramov-Ivićc ${ }^{c}$,Zoltán Kónya ${ }^{\mathrm{d}, \mathrm{e}}$, Slobodan Petrović ${ }^{\mathrm{f}}$, Andrzej Bobrowski ${ }^{\mathrm{g}}$ \\ ${ }^{a}$ Department of Chemistry, Biochemistry and Environmental Protection, Faculty of Sciences, University of Novi Sad, Trg D. Obradovića 3, 21000 Novi Sad, \\ Serbia \\ ${ }^{\mathrm{b}}$ Faculty of Farmacy, Department of Organic Chemistry, University of Belgrade, Vojvode Stepe 450, 11221 Belgrade, Serbia \\ ${ }^{\mathrm{c}}$ ICTM, Institute of Electrochemistry, University of Belgrade, Njegoševa 12, 11000 Belgrade, Serbia \\ d Department of Applied and Environmental Chemistry, University of Szeged, Rerrich Bélatér 1, 6720 Szeged, Hungary \\ e MTA-SZTE Reaction Kinetics and Surface Chemistry Research Group, Rerrich Bélatér 1, 6720 Szeged, Hungary \\ ${ }^{\mathrm{f}}$ Faculty of Technology and Metallurgy, University of Belgrade, Karnegijeva 4, 11000 Belgrade, Serbia \\ ${ }^{\mathrm{g}}$ AGH University of Science and Technology, Faculty of Materials Science and Ceramics, Al. Mickiewicza 30, 30-059 Kraków, Poland
}

\section{A R T I C L E I N F O}

\section{Article history:}

Received 2 December 2016

Received in revised form 19 January 2017

Accepted 22 January 2017

Available online 23 January 2017

\section{Keywords:}

Macrolide antibiotics

Square wave adsorptive stripping

voltammetry

Renewable silver-amalgam film electrode

${ }^{1} \mathrm{H}$ NMR

\begin{abstract}
A B S T R A C T
The renewable silver-amalgam film electrode $(\mathrm{Hg}(\mathrm{Ag}) \mathrm{FE})$ was applied for voltammetric characterization and determination of semi-synthetic macrolide antibiotics azithromycin (AZI), clarithromycin (CLA) and roxithromycin (ROX) in the Britton-Robinson buffer as supporting electrolyte ranging the $\mathrm{pH}$ from 4.0 to 11.9. All three macrolides showed reduction signals in fairly negative potential range.

During direct cathodic square wave voltammetric (SWV) investigations conducted over the potential range from $-0.75 \mathrm{~V}$ to $-2.00 \mathrm{~V}$ vs SCE, either one or two reduction peaks were obtained in the potential range from -1.5 to $-1.9 \mathrm{~V}$. The shapes and intensities of the signals depend on the applied $\mathrm{pH}$ values in wider $\mathrm{pH}$ ranges. For analytical purposes concerning the development of direct cathodic SWV and adsorptive stripping SWV (SW-AdSV) methods the neutral and slightly alkaline media were suitable as $\mathrm{pH} 7.2$, pH 7.4 and pH 7.0 for AZI, CLA and ROX, respectively. Based on the cyclic voltammograms recorded at these $\mathrm{pH}$ values, adsorption-controlled electrode kinetics process can be proposed for all three macrolides. Furthermore, the water suppressed ${ }^{1} \mathrm{H}$ NMR measurements in the $\mathrm{pH}$ range between 6.0 and 10.5 indicated that the macrolide molecules at the optimal analytical conditions are predominantly in protonated form via their tertiary amino groups which supported in all three cases their adsorption on the appropriately polarized $\mathrm{Hg}(\mathrm{Ag}) \mathrm{FE}$ electrode. The optimized direct cathodic SWV methods showed good linearity in concentration ranges $4.81-23.3 \mu \mathrm{g} \mathrm{mL}^{-1}, 1.96-28.6 \mu \mathrm{g} \mathrm{mL}^{-1}$ and $1.48-25.9 \mu \mathrm{g} \mathrm{mL}^{-1}$ for AZI, CLA and ROX, respectively. The development of the SW-AdSV methods resulted in the linear responses at lower concentration ranges as $1.0-2.46 \mu \mathrm{g} \mathrm{mL}^{-1}, 0.05-0.99 \mu \mathrm{g} \mathrm{mL}^{-1}$ and $0.10-0.99 \mu \mathrm{g} \mathrm{mL}^{-1}$, for AZI, CLA and ROX, respectively. The relative standard deviation for all developed methods was not higher than $1.0 \%$ except the SWV method for AZI with 4.7\%. In the case of all three investigated macrolide antibiotics the protonated form of the tertiary amino group(s) at appropriate accumulation potential and time favored the adsorption of the ionic form of the target molecules offering the opportunity for the development of SW-AdSV methods for their trace level analysis on $\mathrm{Hg}(\mathrm{Ag}) \mathrm{FE}$. Optimized SW-AdSV method was applied for determination of ROX in pharmaceutical preparation Runac ${ }^{\mathbb{R}}$.

(c) 2017 Elsevier Ltd. All rights reserved.
\end{abstract}

\footnotetext{
* Corresponding author.

E-mail address: valeria.guzsvany@dh.uns.ac.rs (V. Guzsvány).
}

\section{Introduction}

Macrolide antibiotics are a relatively new class of medications [1], and they are widely used in human and veterinary medicine to treat different infections caused by gram-positive and some gramnegative bacteria [2] as well as less common pathogens [3]. They 
are lipophilic molecules consisting of a large lactone ring with 1216 carbon atoms to which one or more amino and/or neutral sugars are linked via a glycoside bond [4]. Erythromycin (ERY), a naturally occurring macrolide, is the first member of this group. It is produced by Streptomyces erythreus during fermentation $[5,6]$ and is a precursor for the synthesis of semi-synthetic macrolide antibiotics such as azithromycin (AZI, Fig. 1A), clarithromycin (CLA, Fig. 1B) and roxithromycin (ROX, Fig. 1C) [7-11]. In the structure of AZI, a methyl-substituted nitrogen atom is incorporated into the lactone ring, thus creating a 15-member lactone ring [12]. CLA and ROX belong to the group of macrolide antibiotics which contain a 14-member lactone ring [11,13]. CLA is synthesized by substituting a methoxy group for the C-6 hydroxyl group of ERY [13], while in the structure of ROX, the erithronolide A lactone ring has been modified with an etheroxime side chain to prevent its deactivation in the gastric environment [11]. Owing to such changes in their structures, these three macrolide antibiotics are more stable under acidic conditions than ERY is [11,14,15].

CLA and AZI have a similar spectrum of activity. They are used for the treatment of upper and lower respiratory tract infections, skin and soft tissue infections and for the prevention and treatment of infections in HIV-positive patients [7], while ROX has a similar antimicrobial spectrum to ERY and is usually used in vivo for the treatment of respiratory infections [16,17]. ROX is characterized by rapid absorption and a long elimination half-time [18]. This antibiotic can be effective when applied in small doses, which represents an advantage in clinical settings [19]. Adverse effects reported in the case of all three macrolide antibiotics are usually gastrointestinal disturbances, and they are mild and less frequent compared with those reported for ERY [20].

Traditionally, the determination of macrolide antibiotic concentrations is performed via microbiological assays [21], but because of their low sensitivity and specificity in some cases they have been replaced with contemporary analytical techniques [22]. The most commonly used technique for the determination of macrolide antibiotics is liquid chromatography combined with coupled mass spectrometric detection [23]. The diode array detector is not so powerful due to the lack of sensitive chromophore(s) of these antibiotics, but chemical derivatization can increase its sensitivity [24]. According to European Pharmacopeia 5.0, the determination of all three macrolide is based on liquid chromatography with working wavelengths in the UV range - at $215 \mathrm{~nm}$ for AZI and at $205 \mathrm{~nm}$ for CLA and ROX. Based on the proposed methods, gradient elution in the case of CLA and ROX and isocratic elution for AZI on different types of octadecylsilyl stationary phases are recommended [25].

Voltammetric measurements are suitable for the characterization and/or determination of selected macrolide antibiotics either in the case of their oxidation [26-31] or reduction [32-35]. As far as oxidation is concerned, one oxidative peak was recorded for AZI at a carbon paste electrode [26], glassy carbon electrode [27], and polycrystalline gold electrode; the behavior of CLA was similar in the case of the polycrystalline gold electrode [28]. For ROX, an anodic signal was observed at a bare gold electrode [29], poly(3,4-ethylenedioxythiophene)-modified gold electrode [30] and at a glassy carbon electrode modified with single-wall carbon nanotubes [31]. The above-mentioned methods utilized mainly buffered solutions with a pH of 4.6 [26] or $7.0[27,31]$ and the reported peak potentials $\left(\mathrm{E}_{\mathrm{p}}\right)$ were between $0.6 \mathrm{~V}$ and $0.9 \mathrm{~V}$ [26-31]. Beside of cyclic voltammetric characterizations this technique was used for the analytical purposes in the sub and lower $\mathrm{mg} \mathrm{mL}^{-1}$ ranges for AZI [28] and ROX [29], while the poly (3,4-ethylenedioxythiophene) modified gold electrode is suitable for ROX determination in lower concentration range from 0.067 to $16.74 \mu \mathrm{g} \mathrm{mL}^{-1}$ [30]. The lowest limit of quantitation (LOQ) as $1.544 \mathrm{ng} \mathrm{mL}^{-1}$ was reported for AZI and it is related to a SW-AdSV method [26]. For the reduction of ERY [32], its ethylsuccinate (EES) [33] and CLA [34], the hanging mercury drop electrode (HMDE) was applied. One reduction peak of ERY was obtained at the HMDE at $-1.20 \mathrm{~V}$ when using adsorptive stripping voltammetry in a $0.025 \mathrm{~mol} \mathrm{~L}^{-1}$ borate buffer with a $\mathrm{pH}$ of 11.6 , and the LOQ was $2 \cdot 10^{-7} \mathrm{~mol} \mathrm{~L}^{-1}\left(0.15 \mu \mathrm{g} \mathrm{mL} \mathrm{m}^{-1}\right)$ for $120 \mathrm{~s}$ of preconcentration at $-0.9 \mathrm{~V}$ [32]. Recently, a renewable silver-amalgam film electrode $(\mathrm{Hg}(\mathrm{Ag}) \mathrm{FE})$ was applied to study the reduction of EES, the analytical signal of which appeared in a fairly negative potential range, and a trace-level adsorptive stripping voltammetric method was used to determine its concentration in a selected pharmaceutical preparation and in a spiked urine sample [35].

It is well-known that the $\mathrm{Hg}(\mathrm{Ag}) \mathrm{FE}$ is a relatively new type of amalgam-based electrodes [36-39], and provides an alternative to the hanging mercury drop electrode due to their similar electrochemical characteristics [40]; the $\mathrm{Hg}(\mathrm{Ag}) \mathrm{FE}$ enables the determination of a wide range of analytes, including different organic compounds [35,41-54]. For example, it was used for the determination of the levels of some medications, such as EES [35], doxorubicin [41], closantel [42], moroxydine [43], ambazone [44], proguanil [45], prednisolone [46] in spiked urine samples [35,41,43-45] and in pharmaceutical preparation [35,42,44-46]. $\mathrm{The} \mathrm{Hg}(\mathrm{Ag}) \mathrm{FE}$ was also successfully applied for the quantitation of some neonicotinoid insecticides [47-51] in various matrices, such as spiked river water [48-50], commercial formulations [48,49], corn seed [50], spiked honey [48] and carrot juice [51]. Furthermore, the herbicide aclonifen was determined in spiked water samples and the fungicide fenoxanil in spiked river water and spiked rice samples [52,53]. The ability to easily and quickly refresh the electrode surface before each measurement allows the $\mathrm{Hg}(\mathrm{Ag}) \mathrm{FE}$ to be applied in adsorptive stripping measurements [39], as in the case of EES [35], doxorubicin [41], closantel [42] and chlornitrofen [54].

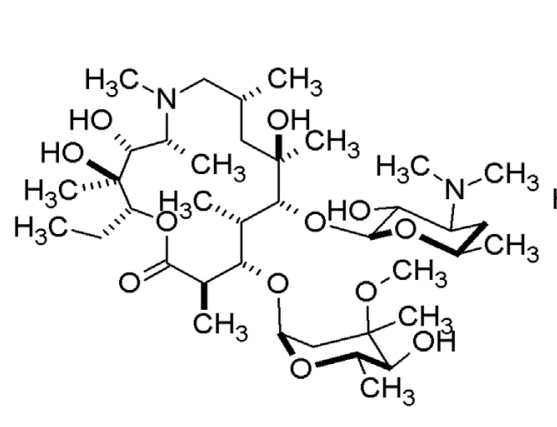

$\mathbf{A}$

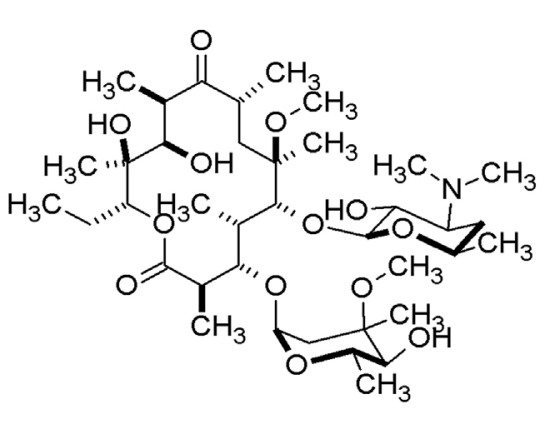

B

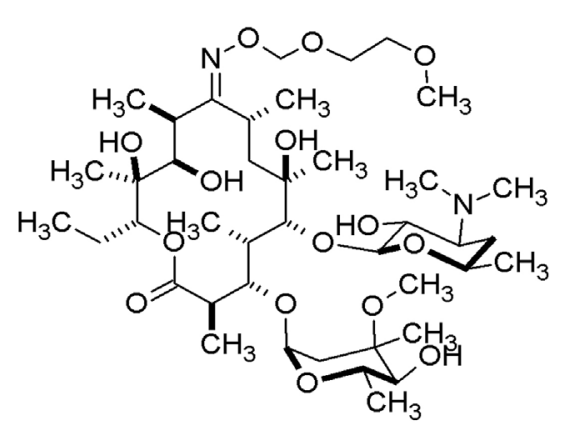

C

Fig. 1. Molecular structure of azithromycin (A), clarithromycin (B) and roxithromycin (C). 
When considering the structure of EES and its affinity to the $\mathrm{Hg}$ (Ag)FE under optimized measurement conditions [35] and the three semi-synthetic macrolide antibiotic target analytes, it can be noted that - beside of different possible electroactive centers - all of them are amines, with $\mathrm{pK}_{\mathrm{a}}$ values between 8.1 and 9.5 (for more details see Table 1) [55-68].

As a follow-up to the afore-mentioned research related to EES [35], in the presented work the voltammetric behavior of AZI, ROX and CLA at the $\mathrm{Hg}(\mathrm{Ag}) \mathrm{FE}$ was investigated by means of optimized direct square wave voltammetric (SWV) and cyclic voltammetric (CV) measurements. The influence of the $\mathrm{pH}$ of the supporting electrolyte on the generation of the reduction signals in the case of all three macrolides was studied in the $\mathrm{pH}$ range from 4.0 to 11.9. Additionally, a detailed investigation concerning the adsorptive stripping square wave voltammetric (SW-AdSV) determination of trace levels of all three target analytes was performed. The possible protonation of the tertiary amino groups was studied via ${ }^{1} \mathrm{H}$ NMR experiments, by measuring their chemical shifts $\left(\delta_{(\mathrm{H})}(\mathrm{ppm})\right)$ for different $\mathrm{pH}$ values of the Britton-Robinson buffer media/ supporting electrolyte, because the protonated form of the molecules can significantly affect SW-AdSV measurements.

\section{Experimental}

\subsection{Reagents and solutions}

All chemicals used were of analytical reagent grade. Individual stock solutions of AZI (from azithromycin dihydrate), CLA and ROX with same concentration of $100.0 \mu \mathrm{g} \mathrm{mL}^{-1}$ were prepared in the mixture of double distilled water: methanol in ratio 70\%: $30 \%(\mathrm{~V} / \mathrm{V})$ for AZI, and 80\%: 20\% (V/V) for CLA and ROX under ultrasound treatment in 30 minutes. All three macrolide standards are from Hemofarm a.d., Pharmaceutical-Chemical Industry, Vršac, Serbia.

Aqueous Britton-Robinson buffer solutions, as supporting electrolyte in voltammetric measurements, were prepared from a stock solution containing $0.04 \mathrm{~mol} \mathrm{~L}^{-1}$ phosphoric acid (Merck, Darmstadt, Germany), boric acid (Merck) and acetic acid (Merck), respectively, by adding $0.2 \mathrm{~mol} \mathrm{~L}^{-1}$ sodium hydroxide (Merck) to obtain the required $\mathrm{pH}$ values, covering the $\mathrm{pH}$ range of $4.0-11.9$. These buffer solutions also served as one of the main components of the media in the case of water-suppressed ${ }^{1} \mathrm{H}$ NMR investigations.

For the ${ }^{1} \mathrm{H}$ NMR measurements pharmaceutical preparations manufactured by Hemofarm a.d., Pharmaceutical-Chemical Industry, Vršac, Serbia (Hemomycin ${ }^{\circledR}$ (nominal AZI content - 250 mg per capsule) and Clathrocyn ${ }^{\circledR}$ (nominal CLA content - $250 \mathrm{mg}$ per tablet)) and by Jugoremedija a.d., Pharmaceutical Industry Zrenjanin, Serbia (Runac ${ }^{\mathbb{R}}$ (nominal ROX content - $150 \mathrm{mg}$ per tablet)) were applied. Appropriate amounts of the commercial preparation of all three macrolide antibiotics were dissolved individually in a mixture of $\mathrm{D}_{2} \mathrm{O}$ (Sigma Aldrich, 99\% atom D, without internal standard) and Britton-Robinson buffer in the ratio of $50 \%$ : $50 \%,(\mathrm{~V} / \mathrm{V})$. Additionally, into every system 2 vol\% of methanol (Merck) was added. The applied Britton-Robinson buffer $\mathrm{pH}$ values were all in the $\mathrm{pH}$ range between 6.0 to 10.5 , with the following specific values: $6.8,7.0,7.2,7.4,8.0,8.2,8.4,8.6$, and 8.8 for AZI, 6.0, 7.2, 7.4, 8.0, 8.4, 8.7, 8.9, and 9.2 for CLA and 6.0, 7.0, 7.4,
8.0, 8.2, 8.4, 9.0, and 10.5 for ROX. The suspensions prepared in this way were treated with ultrasound for 60 minutes and then filtered by means of $0.22 \mu \mathrm{m}$ syringe filters (Kinesis, Reg. Cellulose). The concentration of each of the three macrolides in such solutions was close to $24 \mathrm{mg} \mathrm{mL}^{-1}$. From the obtained liquid phases, aliquots of $600 \mu \mathrm{L}$ were transferred using a micropipette into $5 \mathrm{~mm}$ NMR tubes (Aldrich ${ }^{\circledR}$ ) and ${ }^{1} \mathrm{H}$ NMR measurements were performed. External calibration was performed using 4,4-dimethyl-4-silapentane-sulfonic acid (DSS) by preparing blank samples for all applied $\mathrm{pH}$ values. These blank samples were prepared by mixing the Britton-Robinson buffer with the appropriate $\mathrm{pH}$ value, $\mathrm{D}_{2} \mathrm{O}$ with $1 \% \mathrm{w} / \mathrm{w}$ DSS and $\mathrm{D}_{2} \mathrm{O}$ (without DSS) in the ratio of $50 \%: 25 \%: 25 \%$, $\mathrm{V} / \mathrm{V}$. Into this solution $2 \mathrm{vol} \%$ of methanol (Merck) was added.

For the voltammetric analysis of the farmaceutical preparation the appropriate mass of Runac ${ }^{\circledR}$ tablet was dissolved in the mixture of double distilled water and methanol (65\%: $35 \%, \mathrm{~V} / \mathrm{V})$ to obtaining nominal ROX concentration of $150 \mu \mathrm{g} \mathrm{mL}^{-1}$. These samples were filtered by $0.22 \mu \mathrm{m}$ syringe filters (Kinesis, Reg. Cellulose) before the voltammetric experiments.

\subsection{Apparatus}

Voltammetric measurements were performed on PalmSens electrochemical analyzer operated via software program PSTrace 3.0. A three electrode system was applied with a renewable $\mathrm{Hg}(\mathrm{Ag})$ FE (MTM Anko Instruments, Cracow, Poland [69]) of a $12-\mathrm{mm}^{2}$ surface area as working, a saturated calomel electrode as reference, and a platinum as auxiliary electrode.

${ }^{1} \mathrm{H}$ NMR spectra were recorded on a Bruker AVANCE III HD $400 \mathrm{MHz}$ spectrometer (Bruker), equipped with Prodigy cooled probe head. For some measurements BBFO probe head was used.

The $\mathrm{pH}$ measurements were made by using a combined glass electrode on a previously calibrated $\mathrm{pH}$-meter (Radiometer).

The ultrasound supported macrolide dissolutions were performed by Bandelin (Sonorex digitec) ultrasound bath.

\subsection{Procedures}

\subsubsection{Voltammetry}

2.3.1.1. Application of the $\mathrm{Hg}(\mathrm{Ag}) \mathrm{FE}$. Before use, the surface of the $\mathrm{Hg}(\mathrm{Ag}) \mathrm{FE}$ was chemically cleaned in a $2 \% \mathrm{HNO}_{3}$ solution for about 5 min and then covered with a new amalgam film by immersing it in the internal amalgam pool of the electrode $[47,48]$. The $\mathrm{Hg}(\mathrm{Ag}) \mathrm{FE}$ required electrochemical activation before initial measurements in the chosen supporting electrolyte by cycling the potential in the range from -0.20 to $-1.60 \mathrm{~V}$ over the course of around 20 cycles $[35,41,47]$. Furthermore, in every set of measurements, subsequent voltammetric curves were recorded for a renewed electrode surface, which was achieved by simply dipping the silver amalgam wire into the amalgam pool.

2.3.1.2. Voltammetric experimental conditions. The voltammetric behavior of AZI, CLA and ROX was investigated by means of SWV and CV measurements in Britton-Robinson buffer supporting electrolytes with $\mathrm{pH}$ from 4.0 to 11.9. In all experiments, including the characterization and determination of the target analytes, the

Table 1

Values of the logarithm of dissociation constants $\left(\mathrm{pK}_{\mathrm{a}}\right)$ for azithromycin, clarithromycin and roxithromycin, according to literature data.

\begin{tabular}{|c|c|c|c|}
\hline Macrolide antibiotic & $\mathrm{pK}_{\mathrm{a}}$ & $\mathrm{pK}_{\mathrm{a} 1}$ & $\mathrm{pK}_{\mathrm{a} 2}$ \\
\hline Azithromycin [55-58] & & $8.6 ; 8.7 ; \sim 8.7 ; 8.1$ & $9.5 ; \sim 9.3 ; 8.9$ \\
\hline Clarithromycin [56,59-62] & $8.9 ; 8.99 ; 9.0 ; 8.76$ & & \\
\hline Roxithromycin [63-68] & $9.2 ; 9.17 ; 8.82 \pm 0.04$ & & \\
\hline
\end{tabular}


appropriate volume of the stock solution of the target analyte was added by micropipette into the voltammetric vessel, which contained double-distilled water $(5.0 \mathrm{~mL})$ and the corresponding Britton-Robinson buffer solution $(5.0 \mathrm{~mL})$. The solutions without macrolides served as blank samples.

In the case of the experiments with the macrolides, SW and CV voltammograms were recorded in the potential range from $-0.75 \mathrm{~V}$ to $-2.00 \mathrm{~V}$ with negative ongoing polarization. The CV experiments were performed for $\mathrm{pH}$ values of 7.2, 7.4 and $\mathrm{pH} 7.0$ with scan rates $(\mathrm{v})$ between $0.025 \mathrm{~V} \mathrm{~s}^{-1}$ and $0.18 \mathrm{~V} \mathrm{~s}^{-1}, 0.025 \mathrm{~V} \mathrm{~s}^{-1}$ and $0.45 \mathrm{~V} \mathrm{~s}^{-1}, 0.01 \mathrm{~V} \mathrm{~s}^{-1}$ and $0.20 \mathrm{~V} \mathrm{~s}^{-1}$ in the case of AZI, CLA, and ROX, respectively. The optimized SWV parameters were as follows: a step potential of $5 \mathrm{mV}$, a pulse amplitude of $20 \mathrm{mV}$, and a frequency of $50 \mathrm{~Hz}$. During the optimization of the SW-AdSV procedure, the accumulation potential $\left(\mathrm{E}_{\mathrm{acc}}\right)$ was studied in the potential range from $-0.50 \mathrm{~V}$ to $-1.60 \mathrm{~V}$ for AZI and from $-0.5 \mathrm{~V}$ to $-1.50 \mathrm{~V}$ for CLA and ROX. The accumulation time $\left(\mathrm{t}_{\mathrm{acc}}\right)$ varied from $0 \mathrm{~s}$ to $60 \mathrm{~s}$ in $5 \mathrm{~s}$ increments for all macrolides, while the selected constant $E_{\text {acc }}$ values were maintained. For the SW-AdSV measurements, the SWV parameters were the same as in the case of direct cathodic SWV measurements. The limit of detection (LOD) and the LOQ were evaluated as the macrolide signal-to-baseline-noise ratio of three and ten, respectively.

2.3.1.3. Voltammetric determination ROX in pharmaceutical preparation. Standard addition method was used for the determination of ROX content in Runac ${ }^{\circledR}$ tablet. Appropriate volume of the dissolved and filtered sample made from adequate amount of Runac ${ }^{\circledR}$ tablet was injected into the voltammetric vessel contained $5.0 \mathrm{~mL}$ of Britton-Robinson buffer $\mathrm{pH} 7.0$ and $5.0 \mathrm{~mL}$ of double distilled water. In the next steps three standard additions of ROX were performed with following final concentrations in the voltammetric vessel: $0.10 ; 0.20$ and $0.30 \mu \mathrm{g} \mathrm{mL}^{-1}$. The measurement parameters of SW-AdSV method were as follows: $\mathrm{E}_{\mathrm{acc}}-1.05 \mathrm{~V}, \mathrm{t}_{\mathrm{acc}} 15 \mathrm{~s}$, step potential $5 \mathrm{mV}$, pulse amplitude $20 \mathrm{mV}$ and frequency $50 \mathrm{~Hz}$.

\subsection{2. ${ }^{1} \mathrm{H}$ NMR measurements}

All ${ }^{1} \mathrm{H}$ NMR measurements were performed in water suppressed working mode $[35,70]$ with external calibrations by means of DSS. The experimental conditions were as follows: the standard Bruker pulse program (zgpr) was used for the water suppression, spectral window was $6000 \mathrm{~Hz}, 90^{\circ}$ pulse length $15 \mu \mathrm{s}, 32$ scans, sample temperature was $298 \mathrm{~K}$.

\section{Results and discussion}

\subsection{Voltammetric characterization of azithromycin, clarithromycin and roxithromycin at $\mathrm{Hg}(\mathrm{Ag}) \mathrm{FE}$}

As first, direct cathodic SWV characterization of the three target analytes were performed individually in a fairly negative potential range from $-0.75 \mathrm{~V}$ to $-2.00 \mathrm{~V}$ in the Britton-Robinson buffers ranging the $\mathrm{pH}$ values from 4.0 to 11.9. Based on the peak shapes of obtained reduction signals, which are characterized by $E_{p}$ and peak intensity $\left(\mathrm{I}_{\mathrm{p}}\right)$, they appeared between -1.5 and $-1.9 \mathrm{~V}$ vs SCE, and in some cases were greatly affected by applied pHs. Fig. 2 illustrates the selected characteristic responses concerning the appropriate baselines (A) and target analytes AZI (B), CLA (C) and ROX (D). As it can be seen, in the acidic media there are no remarkable signals from the analytes, probably because of their overlapping character with the hydrogen evaluation signals closing on such way the potential window on $\mathrm{Hg}(\mathrm{Ag}) \mathrm{FE}$. In the case of CLA and ROX the first recognizable peaks appeared at $\mathrm{pH} 4.0$, while in the case of AZI at $\mathrm{pH} 6.0$, in all cases they are hardly evaluable. By the increase of the $\mathrm{pH}$ value of the supporting electrolyte up to $\mathrm{pH} 10.0$, in the case of all three investigated compounds, one main peak, convenient for the analytical purpose, was formed nearly from $-1.9 \mathrm{~V}$ to $-1.6 \mathrm{~V}$ for AZI, and very similarly between $-1.7 \mathrm{~V}$ and $-1.5 \mathrm{~V}$ for CLA and ROX. In the case of CLA, a second peak is appeared in a very similar potential range that characterizes the AZI main peak. The $E_{p}$ of the main peak for all three target analyte was shifted to more positive potential values as it is clearly visible on the appropriate sets of
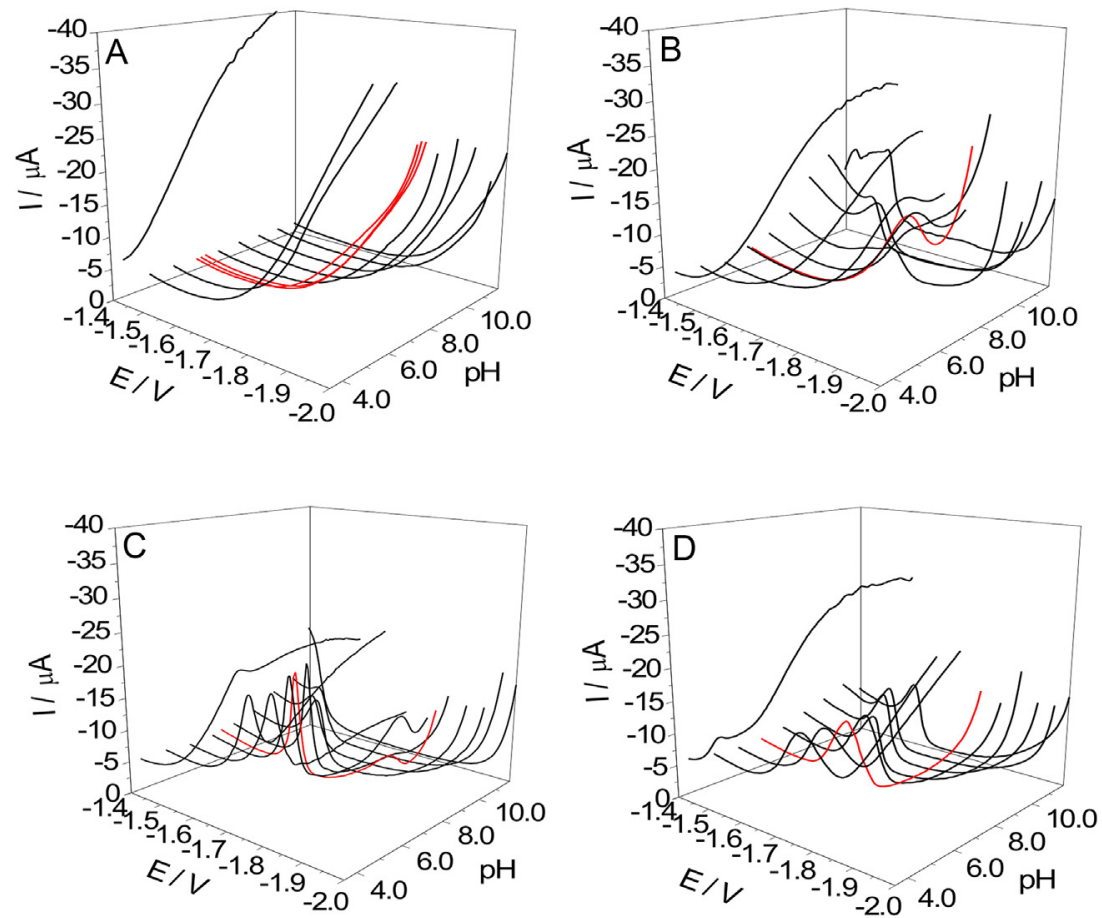

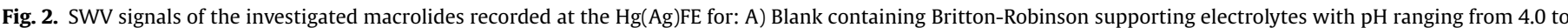

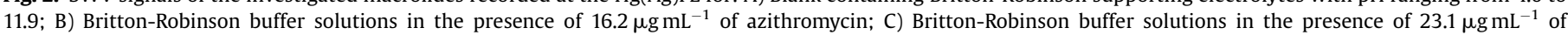

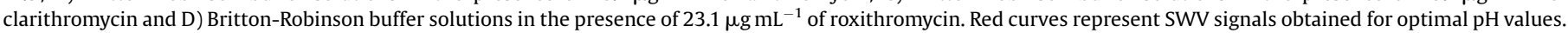


SWV curves (Fig. 2), and elaborated on the $\mathrm{E}_{\mathrm{p}}$-pH diagrams (Fig. 3, insets) for AZI (A), CLA (B), and ROX (C). Such behavior is in accordance with the recently reported behavior of EES on $\mathrm{Hg}(\mathrm{Ag}) \mathrm{F}$ [35] and $\mathrm{Hg}$ [33] working electrodes. Furthermore, in the case of all three macrolides the reduction signals with highest symmetry and $I_{p}$ values appeared in neutral and slightly alkaline media, while at $\mathrm{pH}$ upper then 8.0 the reduction signal decreased significantly as is it presented in Fig. 2 by SWV signals and in numerical form as $I_{\mathrm{p}}-\mathrm{pH}$ dependence on Fig. 3 for AZI (A), CLA (B) and ROX (C), respectively.

When the $\mathrm{pH}$ of the supporting electrolyte was modified in $0.2 \mathrm{pH}$ steps, some signal characteristics of the target analytes at the $\mathrm{Hg}(\mathrm{Ag}) \mathrm{FE}$ are clearly recognizable. Namely, at $\mathrm{pH}$ values between $\mathrm{pH} 7.0$ and $\mathrm{pH} 9.0$, in some cases the AZI reduction peak has a split character with measurable $\mathrm{E}_{\mathrm{p}}$ values close to $-1.7 \mathrm{~V}$ and $-1.8 \mathrm{~V}$. When the concentration of the target analyte was increased, the peak at $-1.8 \mathrm{~V}$ showed proportional changes with regard to its $I_{p}$ value while in the case of the peak with $E_{p}$ close to $-1.7 \mathrm{~V}$ this was not the case. This signal became lower with
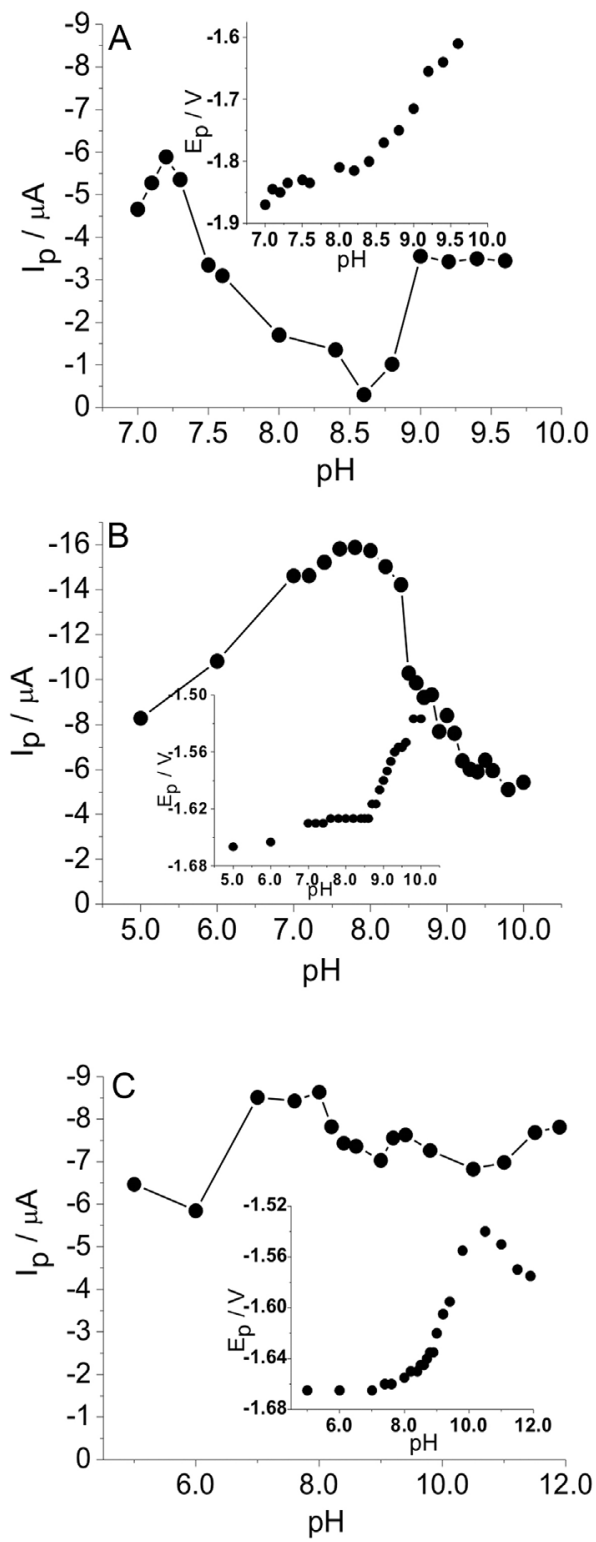

Fig. 3. Dependences of peak currents, $I_{p}(A, B, C)$, versus $p H$ for the investigated macrolide antibiotics: A) azithromycin (16.2 $\left.\mu \mathrm{g} \mathrm{mL}^{-1}\right)$; B) clarithromycin (23.1 $\mu \mathrm{g}$ $\left.\mathrm{mL}^{-1}\right)$ and $\mathrm{C}$ ) roxithromycin $\left(23.1 \mu \mathrm{g} \mathrm{mL}^{-1}\right)$. Insets: appropriate dependences of peak potential, $\mathrm{E}_{\mathrm{p}}$, versus $\mathrm{pH}$. Supporting electrolyte: Britton-Robinson buffers. increased AZI concentrations; at concentrations higher than $10 \mu \mathrm{g} \mathrm{mL}^{-1}$, it was hardly recognizable on the SWV curves. At $\mathrm{pH}$ values between 9.0 and 10.0 the peak did not have a split form. Furthermore, between $\mathrm{pH} 10.0$ and 11.9 the reduction signal was almost non-distinguishable from the signal of the baseline and it was not sufficient for analysis. This phenomenon can be explained by a lack of protons, which can participate or promote the electron exchange reduction step, but at the same time can be related to some chemical changes in the structure of the macrolide, such as a possible opening of the macrolide ring [71].

In the case of CLA, between $\mathrm{pH} 4.0$ and 8.0 one reduction signal was recorded, and this signal between the pHs 7.0 and 8.0 with $\mathrm{E}_{\mathrm{p}}$ close to $-1.6 \mathrm{~V}$ is fully distinguished from the proton evolution signal, obtaining sharp and symmetrical shape. Additionally, likely due to the broadening of the potential window of $\mathrm{Hg}(\mathrm{Ag}) \mathrm{FE}$ in neutral and slightly alkaline media, a further reduction signal at a maximum close to $-1.9 \mathrm{~V}$ was recognized, which can be attributed maybe to the reduction of the lactonic carboxyl group in the system or can be related to some effects related to protons on the tertiary amino groups. At $\mathrm{pH}$ values higher than 8.5 , the $\mathrm{I}_{\mathrm{p}}$ value of CLA decreased, probably because of the deficiency of protons. When the $\mathrm{pH}$ value increased from 8.5 to 10.0 , the signal $\mathrm{I}_{\mathrm{p}}$ rapidly decreased, and - as in the case of AZI - between 10.0 and 11.9 this reduction peak was close to $-1.5 \mathrm{~V}$ and it was very close to the baseline.

One reduction signal for ROX was observed in the investigated $\mathrm{pH}$ range between $\mathrm{pH} 4.0$ and 11.9. Its peak potential depends on the $\mathrm{pH}$ in the $\mathrm{pH}$ range between 7.0 and 11.9 , and the difference between ROX and other investigated compounds (AZI and CLA) is noticeable in alkaline solutions, since ROX signals are measurable up to a $\mathrm{pH}$ of 11.9 .

All the above-mentioned differences in reduction signals can likely be explained by the diversity of the possible electroactive centers recognized as the keto group for the CLA main signal, as in the case of EES [35], imino group for ROX [72], and carboxylic keto or protons on the tertiary amino groups for AZI. In any case, the slope of the $\mathrm{E}_{\mathrm{p}} \mathrm{vs}$. $\mathrm{pH}$ plot changed at a $\mathrm{pH}$ of about 8 for all three macrolide antibiotics and the appropriate linear dependences can be described with two linear equations, as elaborated in Table 2 for the selected $\mathrm{pH}$ ranges.

As for the selection of the $\mathrm{pH}$ of the supporting electrolyte for the SWV procedure, the symmetry of the reduction peak and its $I_{p}$ value (Fig. 3) were considered as the two crucial parameters. In the case of SWV measurements, the most intensive signal of AZI (Figs. 2B and $3 \mathrm{~A}$ ) was obtained for a $\mathrm{pH}$ of 7.2 , while in more alkaline media with a $\mathrm{pH}$ of up to 8.6 , the intensity of the reduction peak decreased significantly, probably due to its split character. From pH 8.6 and up to 9.0, the AZI response increased, while between 9.0 and 9.6 it was almost constant at around $60 \%$ of the $\mathrm{I}_{\mathrm{p}}$ value for the $\mathrm{pH}$ of 7.2. Hence, for developing the direct cathodic SWV method for AZI determination as the $\mathrm{pH} 7.2$ was selected.

In the case of CLA (Figs. $2 \mathrm{C}$ and $3 \mathrm{~B}$ ), the most intensive reduction signal was obtained for a $\mathrm{pH}$ close to 8 , but this peak exhibited very similar characteristics in a wider $\mathrm{pH}$ range, i.e. from 7.4 to 8.2. Based on the shape/symmetry of the reduction peak, the $\mathrm{pH}$ of 7.4 was selected as the optimal value for the determination of CLA, even though the signal is $3 \%$ lower in comparison to that for a $\mathrm{pH}$ of 8.0.

Based on the results obtained for ROX (Figs. 2D and 3C), the most intensive reduction peak of the target analyte was observed in the $\mathrm{pH}$ range from 7.0 to 8.0. Thanks to the appropriate shape and $I_{p}$ value of the ROX reduction signal, the $\mathrm{pH}$ of 7.0 was determined to be the optimal value for direct SWV determination. The SWV reduction peaks of AZI (Fig. 4A, $16.2 \mu \mathrm{g} \mathrm{mL}^{-1}$ ), CLA (Fig. 4B, $23.1 \mu \mathrm{g} \mathrm{mL}^{-1}$ ) and ROX (Fig. 4C, $23.1 \mu \mathrm{g} \mathrm{mL}^{-1}$ ) recorded under the optimized experimental conditions - including the 
Table 2

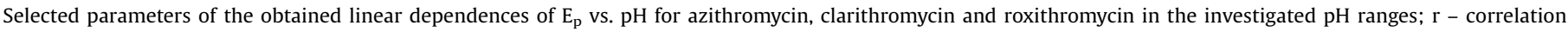
coefficient.

\begin{tabular}{|c|c|c|c|c|c|c|}
\hline \multirow[t]{2}{*}{ Parameters } & \multicolumn{2}{|c|}{ Azithromycin } & \multicolumn{2}{|c|}{ Clarithromycin } & \multicolumn{2}{|c|}{ Roxithromycin } \\
\hline & $\mathrm{pH} 7.0-8.4$ & $\mathrm{pH} 8.4-9.0$ & pH 5.0-8.4 & pH 8.6-9.0 & pH 7.0-8.4 & $\mathrm{pH} 8.4-9.8$ \\
\hline Intercept (V) & -2.138 & -2.955 & -1.71 & -2.446 & -1.744 & -2.222 \\
\hline Slope $(\mathrm{V} / \mathrm{pH})$ & 0.040 & 0.137 & 0.010 & 0.095 & 0.011 & 0.067 \\
\hline $\mathrm{r}$ & 0.937 & 0.995 & 0.955 & 0.975 & 0.980 & 0.979 \\
\hline
\end{tabular}
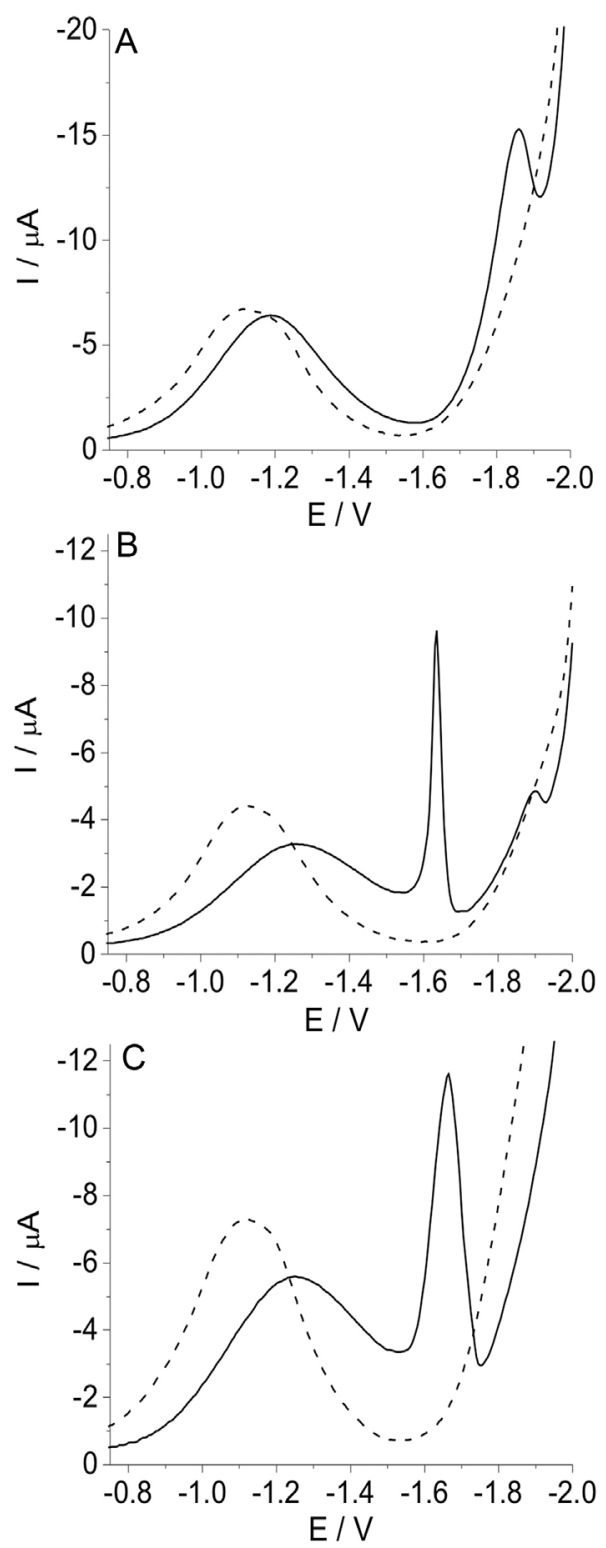

Fig. 4. SW voltammograms of the target macrolide antibiotics obtained in BrittonRobinson supporting electrolyte under optimized experimental conditions for A) azithromycin at $\mathrm{pH} 7.2\left(16.2 \mu \mathrm{g} \mathrm{mL}^{-1}\right.$, full line) and the blank (dashed line); $\mathrm{B}$ ) clarithromycin at $\mathrm{pH} 7.4\left(23.1 \mu \mathrm{g} \mathrm{mL}^{-1}\right.$, full line) and the blank (dashed line) and $\mathrm{C}$ ) roxithromycin at $\mathrm{pH} 7.0\left(23.1 \mu \mathrm{g} \mathrm{mL}^{-1}\right.$, full line) and the blank (dashed line).

optimized voltammetric measurement parameters together with the appropriate baseline signals - are presented in Fig. 4.

Additionally, beside the elaborated analytical signals in all cases a broader reduction peak was observed at about $-1.2 \mathrm{~V}$. This signal was recognized at the appropriate baselines with same characteristics. As it was reported in our earlier papers [35,41,47-49] this signal probably originates from the basic behavior of the $\mathrm{Hg}(\mathrm{Ag}) \mathrm{FE}$ in Britton-Robinson supporting electrolyte. Its presence was reported in acetate and phosphate buffer supporting electrolytes as well [47]. Anyway, this signal has no significant overlapping character with the analytical signals in the case of all three macrolides till $\mathrm{pH} 10$.

To investigate the possible reaction kinetics of all three analytes at the $\mathrm{Hg}(\mathrm{Ag}) \mathrm{FE}, \mathrm{CV}$ experiments were performed in potential range from $-0.75 \mathrm{~V}$ to $-2.00 \mathrm{~V}$ at the optimal $\mathrm{pH}$ values. In all measurements, one main irreversible reduction peak of the target analytes was obtained. For all three investigated macrolides, the linear dependences of the signal intensity of the target analyte vs scan rate $(v)$ were evaluated; the results are presented in Table 3. Based on the numerical data, the $I_{p} v s$ linear dependences have a correlation coefficient close to 1 , which can indicate that the investigated processes are adsorption-controlled ones [73].

After reviewing the $\mathrm{pK}_{\mathrm{a}}$ values of the target analytes given in Table 1, it can be proposed that all three target analytes occur predominantly in their protonated form at $\mathrm{pH}$ values considered optimal for the application of a direct cathodic SWV method.

Based on our earlier experiences, in the case of the macrolide antibiotic derivative EES, its tertiary amino group in protonated form favors the adsorption of the target analyte at a negatively polarized $\mathrm{Hg}(\mathrm{Ag}) \mathrm{FE}$. This effect was exploited when designing an adsorptive stripping SWV method for the determination of trace levels of EES [35]. Because of the expected benefits of a positive charge on the three target macrolides, extensive ${ }^{1} \mathrm{H}$ NMR experiments were performed to investigate the possible protonation of the tertiary amino group of AZI, CLA and ROX at different $\mathrm{pH}$ values via the chemical shift changes of the methyl protons of tertiary amines. The measurements were performed by means of a watersuppressed ${ }^{1} \mathrm{H}$ NMR technique, using the commercially available preparation of the medications (for details, see the experimental protocol) with an external calibration of the spectra by DSS varying the $\mathrm{pH}$ between 6.0 and 10.5. The obtained chemical shifts are listed in Table 4. Furthermore, the full ${ }^{1} \mathrm{H}$ NMR spectrum of CLA at a $\mathrm{pH}$ of 7.4 is showed in Fig. $5 \mathrm{~A}$, and the proton signals of the mentioned methyl groups at different $\mathrm{pH}$ values ranging from 7.2 to 9.2 are presented as Fig. 5B in the form of section plots. The appropriate ${ }^{1} \mathrm{H}$ NMR signals for AZI and ROX are enclosed as Fig. S1 and Fig. S2, respectively.

For all three macrolides - as in the case of EES [35] - the two methyl groups connected to the tertiary amine have significantly different chemical shifts in the protonated/positively charged and

Table 3

Some parameters of the obtained linear dependences $\mathrm{I}_{\mathrm{p}} \mathrm{vs} \mathrm{v}$ for azithromycin, clarithromycin and roxithromycin; $r$ - correlation coefficient.

\begin{tabular}{llll}
\hline \multirow{2}{*}{ Parameters } & $\mathrm{I}_{\mathrm{p}}$ vs $\mathrm{v}$ & & \\
\cline { 2 - 4 } & Azithromycin & Clarithromycin & Roxithromycin \\
\hline $\mathrm{pH}$ & 7.2 & 7.4 & 7.0 \\
Scan rate range $\left(\mathrm{mV} \mathrm{s}^{-1}\right)$ & $25-175$ & $25-450$ & $10-200$ \\
Intercept $(\mu \mathrm{A})$ & -2.258 & 0.0714 & -0.167 \\
Slope $\left(\mu \mathrm{A} / \mathrm{mVs}^{-1}\right)$ & -0.009 & -0.008 & -0.013 \\
$\mathrm{r}$ & -0.995 & -0.999 & -0.996 \\
\hline
\end{tabular}


Table 4

${ }^{1} \mathrm{H}$ chemical shifts of the signals for the $\mathrm{N}, \mathrm{N}$-dimethyl protons of azithromycin, clarithromycin and roxithromycin at selected $\mathrm{pH}$ values.

\begin{tabular}{|c|c|c|c|c|c|}
\hline \multicolumn{2}{|c|}{ Azithromycin } & \multicolumn{2}{|c|}{ Clarithromycin } & \multicolumn{2}{|c|}{ Roxithromycin } \\
\hline $\mathrm{pH}$ & $\delta(\mathrm{H})(\mathrm{ppm})$ & $\mathrm{pH}$ & $\delta(\mathrm{H})(\mathrm{ppm})$ & $\mathrm{pH}$ & $\delta(\mathrm{H})(\mathrm{ppm})$ \\
\hline 6.8 & 2.80 & 6.0 & 2.84 & 6.0 & 2.84 \\
\hline 7.0 & 2.80 & 7.2 & 2.81 & 7.0 & 2.82 \\
\hline 7.2 & 2.75 & 7.4 & 2.80 & 7.4 & 2.78 \\
\hline 7.4 & 2.73 & 8.0 & 2.79 & 8.0 & 2.77 \\
\hline 8.0 & 2.72 & 8.4 & 2.76 & 8.2 & 2.76 \\
\hline 8.2 & 2.69 & 8.7 & 2.68 & 8.4 & 2.74 \\
\hline 8.4 & 2.68 & 8.9 & 2.64 & 9.0 & 2.59 \\
\hline 8.6 & 2.65 & 9.2 & 2.57 & 10.5 & 2.44 \\
\hline 8.8 & 2.63 & & & & \\
\hline
\end{tabular}

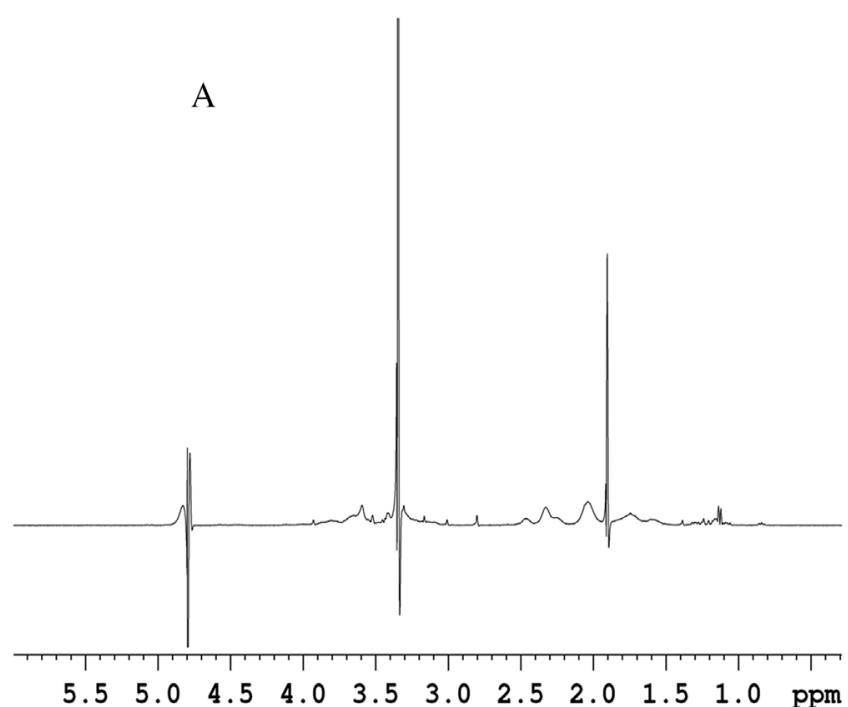

B

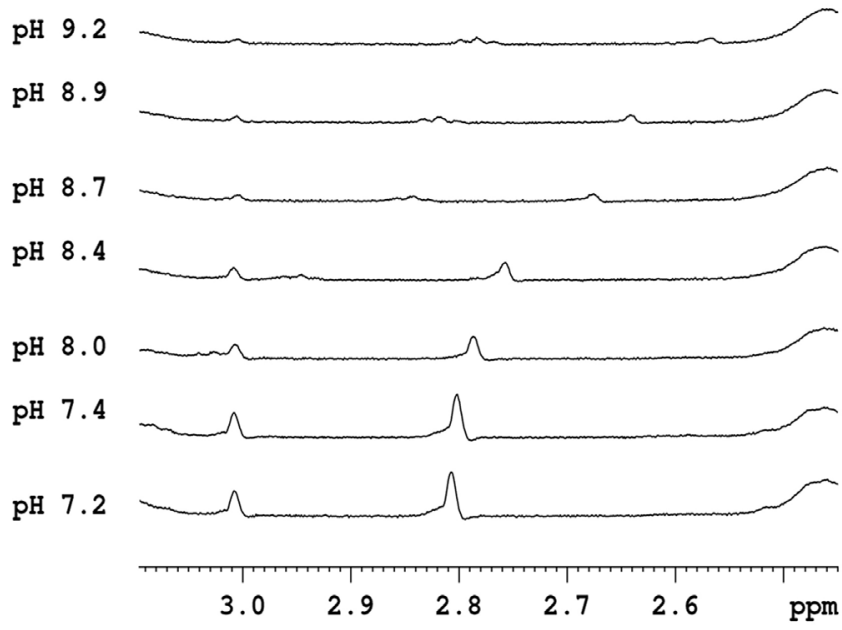

Fig. 5. ${ }^{1} \mathrm{H}$ NMR spectra of clarithromycin at different $\mathrm{pH}$ values of Britton-Robinson buffer with $\mathrm{D}_{2} \mathrm{O}$ : A) Full ${ }^{1} \mathrm{H}$ NMR spectra of clarithromycin at a $\mathrm{pH}$ of 7.4 and $\mathrm{B}$ ) Section plots for $\mathrm{N}, \mathrm{N}$-dimethyl signals recorded for the following $\mathrm{pH}$ values: 7.2, 7.4, 8.0, 8.4, 8.7, 8.9, and 9.2.

deprotonated/uncharged form of the nitrogen atom. In the protonated form for all three macrolides the nitrogen downfield shifts of the target methyl signals were observed (shifted to higher ppm values) because of the differences in the shielding effects of the protonated and deprotonated nitrogen. Therefore, it can be concluded that at pH 7.2, 7.4 and 7.0 the AZI, CLA, and ROX occur in their protonated form, which is consistent with their $\mathrm{pK}_{\mathrm{a}}$ data from the literature (see Table 1).

\subsection{Optimization of the SW-AdSV analytical methods for the selected macrolide antibiotics}

In addition to the optimal selection of the $\mathrm{pH}$ for the target macrolides, which provides well-shaped reduction signals in the direct SWV measurements and allows the formation of protonated amino groups at the same time, two additional key parameters - accumulation potential $\left(\mathrm{E}_{\mathrm{acc}}\right)$ and time $\left(\mathrm{t}_{\mathrm{acc}}\right)-$ were considered. The adsorption behavior of the target analytes was investigated for $E_{\text {acc }}$ ranging from $-0.50 \mathrm{~V}$ to $-1.50 \mathrm{~V}$ for ROX and CLA and from $-0.50 \mathrm{~V}$ to $-1.60 \mathrm{~V}$ for AZI; in all three cases, the applied $t_{a c c}$ was increased from 0 to $60 \mathrm{~s}$ in increments of $5 \mathrm{~s}$ while maintaining $E_{\text {acc }}$ at constant values. Between each measurement, the $\mathrm{Hg}(\mathrm{Ag}) \mathrm{FE}$ was renewed via dipping in the amalgam pool. The $I_{p} v s t_{a c c}$ dependences for the selected $E_{\text {acc }}$ values are presented in Fig. 6(A, C, E) together with some SWV (curves marked $0 \mathrm{~s}$ in plots $\mathrm{B}, \mathrm{D}$, and $\mathrm{F}$ ) and SW-AdSV plots for AZI (B, curves marked 5, 10, 25, and $60 \mathrm{~s}$ ) and for CLA and ROX (D and F, respectively, curves marked 5, 15, 25, and $60 \mathrm{~s}$ ); the voltammograms recorded under the optimized experimental conditions are marked in red.

Although for AZI the most intensive reduction signal was obtained at an $E_{\text {acc }}$ of $-1.45 \mathrm{~V}$ and a $t_{a c c}$ of $15 \mathrm{~s}$, an accumulation time of $10 \mathrm{~s}$ was selected as the optimal accumulation time for the application of the SW-AdSV method because of the higher symmetry of the peak shape. In the case of CLA, the reduction signals obtained for an $\mathrm{E}_{\mathrm{acc}}$ between $-0.50 \mathrm{~V}$ and $-0.70 \mathrm{~V}$ and a $t_{a c c}$ of $10 \mathrm{~s}$ were in some cases similar to those recorded for an $E_{a c c}$ between $-1.0 \mathrm{~V}$ and $-1.25 \mathrm{~V}$, but, unfortunately, the repeatability of these measurements was below the values required of reliable analytical methods. The $\mathrm{E}_{\mathrm{acc}}$ of $-1.05 \mathrm{~V}$ and the accumulation time of $15 \mathrm{~s}$ were selected for CLA determination as the best compromise between the desired signal shape, intensity and reproducibility. During the optimization of the key parameters of the SW-AdSV method for the determination of ROX, the most intensive reduction signal was obtained for $E_{\text {acc }}=-1.00 \mathrm{~V}$ and $t_{a c c}=20 \mathrm{~s}$, but - based on peak shape and the reproducibility of the measurements - the $\mathrm{E}_{\mathrm{acc}}=-1.05 \mathrm{~V}$, and $\mathrm{t}_{\mathrm{acc}}=15 \mathrm{~s}$ were chosen as the optimal parameters. In any case, for all three macrolides and the above-specified optimal $\mathrm{E}_{\mathrm{acc}}$ values, a $\mathrm{t}_{\mathrm{acc}}$ ranging from 10 to $25 \mathrm{~s}$ offered acceptable SW-AdSV measurement conditions. Furthermore, it can be expected that the positively charged macrolides should have a higher affinity for the $\mathrm{Hg}(\mathrm{Ag}) \mathrm{FE}$ with more negative polarization, but - based on the obtained signals it can be proposed that at such potentials and generally in such conditions, competitive hydrogen evolution occurs, which causes the $I_{p}$ to decrease. The same effect was also observed when increasing the $t_{\text {acc }}$ up to $60 \mathrm{~s}$ for the favored $E_{\text {acc. }}$. It should be noted that the direct SWV reduction signals presented in Fig. 6 only serve as an illustration of the qualitative behavior of the systems, because under such experimental conditions the concentrations of all three macrolides are below the LOQ of direct SWV methods.

\subsection{Voltammetric determination of macrolide antibiotics by SWV and SW-AdSV methods}

Using the optimized experimental parameters, direct cathodic SWV and SW-AdSV methods were developed for the determination of all three macrolide antibiotics. The correlation of the concentration of target analytes with the appropriate $I_{p}$ values resulted in linear equations, as shown in Table 5 and 

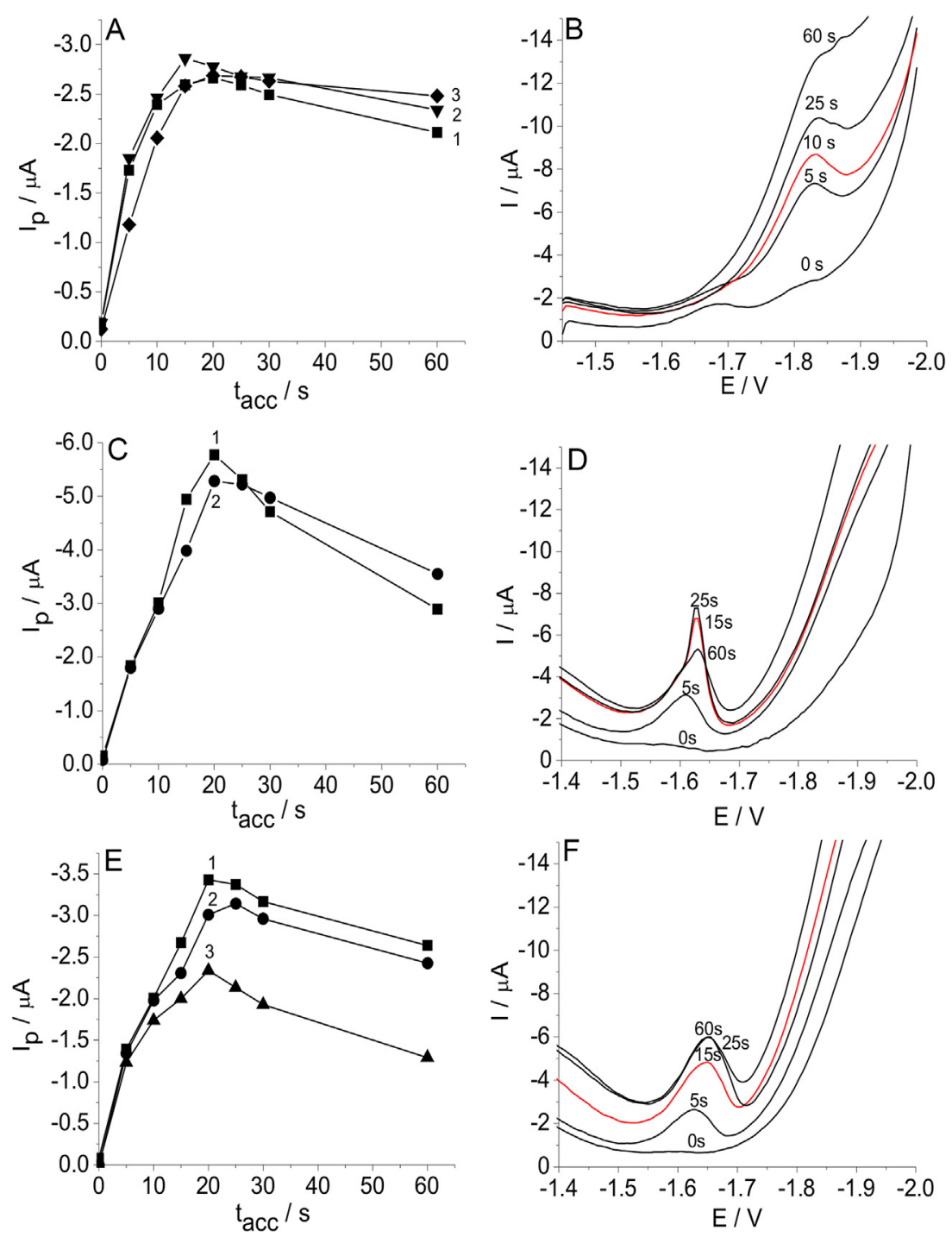

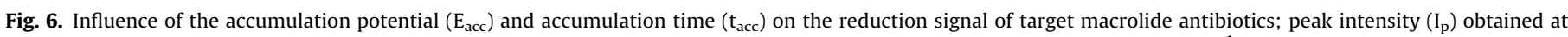

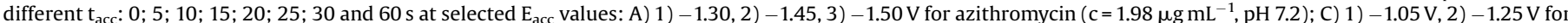

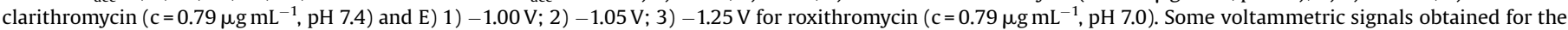
following $\mathrm{E}_{\mathrm{acc}}$ values ( $\mathrm{t}_{\mathrm{acc}}$ values are marked on the curves): $\mathrm{B}$ ) $-1.45 \mathrm{~V}$ (azithromycin); $\mathrm{D}$ ) $-1.05 \mathrm{~V}$ (clarithromycin) and $\mathrm{F}$ ) $-1.05 \mathrm{~V}$ (roxithromycin).

Table 5

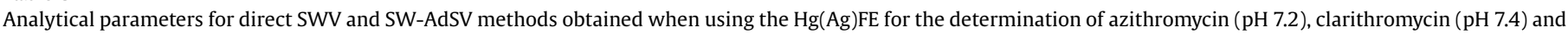
roxithromycin ( $\mathrm{pH}$ 7.0); LOD: limit of detection, LOQ: limit of quantitation.

\begin{tabular}{|c|c|c|c|c|c|c|}
\hline \multirow[t]{2}{*}{ Parameters } & \multicolumn{3}{|l|}{$\mathrm{Hg}(\mathrm{Ag}) \mathrm{FE} / \mathrm{SWV}$} & \multicolumn{3}{|c|}{$\mathrm{Hg}(\mathrm{Ag}) \mathrm{FE} / \mathrm{SW}$-AdSV } \\
\hline & Azithromycin & Clarithromycin & Roxithromycin & Azithromycin & Clarithromycin & Roxithromycin \\
\hline Linear range $\left(\mu \mathrm{g} \mathrm{mL}^{-1}\right)$ & $4.81-23.3$ & $1.96-28.6$ & $1.48-25.9$ & $1.0-2.46$ & $0.05-0.99$ & $0.10-0.99$ \\
\hline Intercept $(\mu \mathrm{A})$ & 0.637 & 0.523 & 0.376 & 0.030 & 0.0879 & 0.085 \\
\hline Slope $\left(\mu \mathrm{A} / \mu \mathrm{g} \mathrm{mL}^{-1}\right)$ & -0.405 & -0.375 & -0.391 & -1.404 & -5.262 & -3.713 \\
\hline Correlation coefficient & -0.994 & -0.997 & -0.998 & -0.995 & -0.999 & -0.999 \\
\hline $\mathrm{LOD}\left(\mu \mathrm{g} \mathrm{mL}^{-1}\right)$ & 1.44 & 0.59 & 0.44 & 0.30 & 0.015 & 0.03 \\
\hline $\mathrm{LOQ}\left(\mu \mathrm{g} \mathrm{mL}^{-1}\right)$ & 4.81 & 1.96 & 1.48 & 1.00 & 0.05 & 0.10 \\
\hline
\end{tabular}

depicted for the CLA in Fig. 7. In all cases, the correlation coefficients of linear equations were equal to or higher than 0.994. As for the direct SWV methods, the highest LOQ was obtained for AZI, probably because of the fact that the analytical signal appeared in a fairly negative potential range and was relatively close to the end of the potential window of $\mathrm{Hg}(\mathrm{Ag}) \mathrm{FE}$ at $\mathrm{a} \mathrm{pH}$ of 7.2 . When the $\mathrm{pH}$ of the supporting electrolyte increased, the potential window expanded, but the sensitivity of the method decreased due to the decreased concentration of protons, which likely supported the electron exchange process. The SWV methods proved to be suitable for the determination of investigated antibiotics at concentrations ranging from several $\mu \mathrm{g} \mathrm{mL} \mathrm{m}^{-1}$ to nearly $25 \mu \mathrm{g} \mathrm{mL}^{-1}$ as the upper concentration range on the calibration curves. The reproducibility of analytical signals was investigated in all three cases; based on six consecutive measurements, the relative standard deviations 

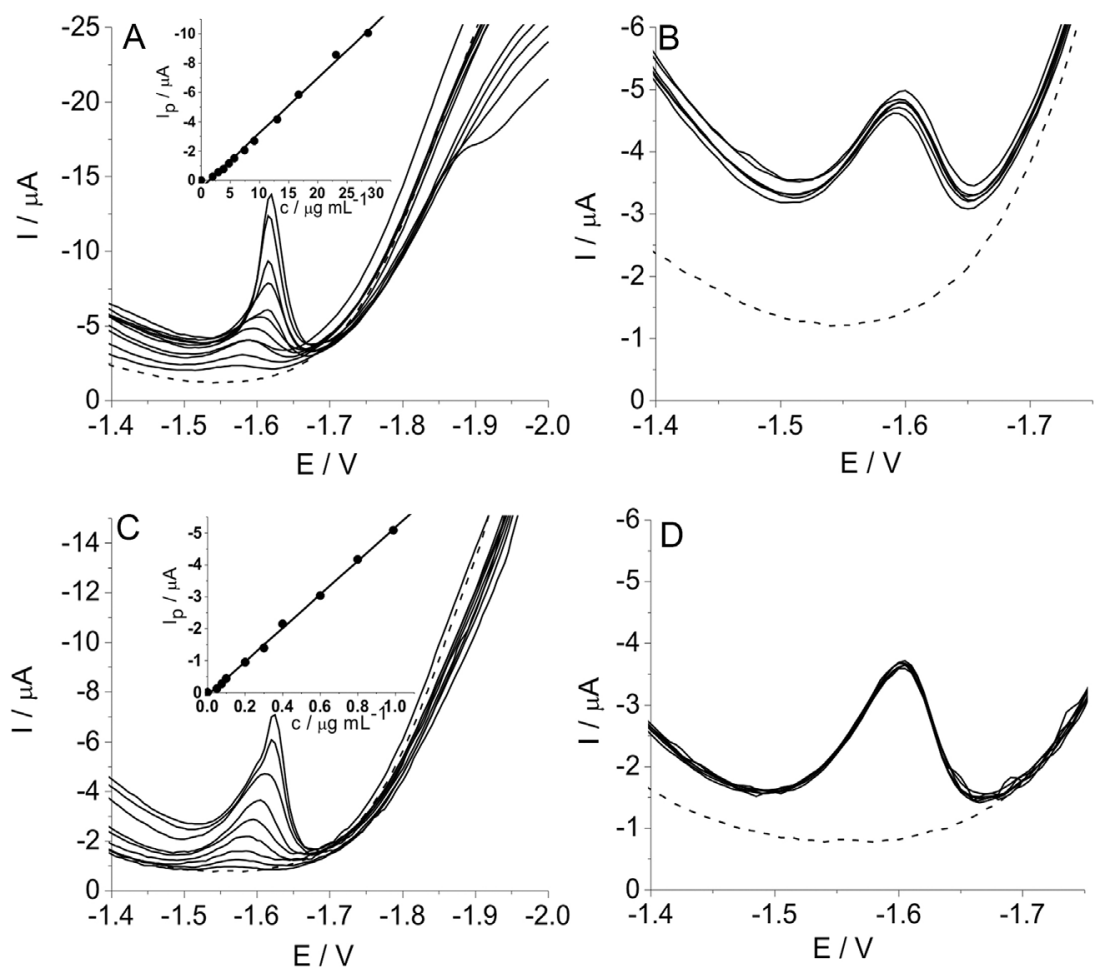

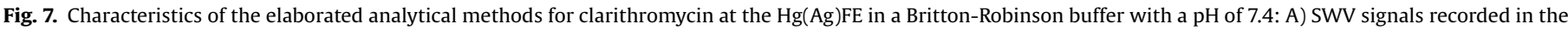

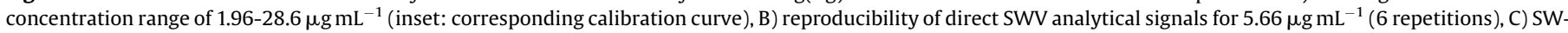

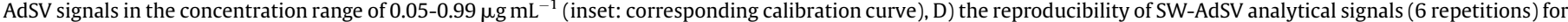
$0.40 \mu \mathrm{g} \mathrm{mL}^{-1}$. Dashed lines represent the voltammograms of the corresponding baselines at $\mathrm{pH}$ 7.4. For SW-AdSV measurements $\mathrm{E}_{\mathrm{acc}}-1.05 \mathrm{~V}$ and $\mathrm{t}_{\mathrm{acc}} 15 \mathrm{~s}$.

(RSD) were $4.7 \%, 0.44 \%$ and $0.88 \%$ for AZI, CLA and ROX, respectively. As for the SW-AdSV methods, the one for CLA had LOQ value of $0.05 \mu \mathrm{g} \mathrm{mL} \mathrm{m}^{-1}$, the LOQ achieved for ROX was $0.10 \mu \mathrm{g} \mathrm{mL}^{-1}$, while in the case of AZI the LOQ was higher and amounted to $1.0 \mu \mathrm{g} \mathrm{mL}^{-1}$. For CLA and ROX the upper concentration of the calibration curve was $0.99 \mu \mathrm{g} \mathrm{mL}^{-1}$, while in the case of AZI it was higher, i.e. $2.46 \mu \mathrm{g} \mathrm{mL}^{-1}$. The RSD of the SW-AdSV procedures did not exceed $1.0 \%$ based on six consecutive measurements for AZI $\left(1.39 \mu \mathrm{g} \mathrm{mL}^{-1}\right)$, CLA $(0.40 \mu \mathrm{g}$ $\left.\mathrm{mL}^{-1}\right)$ and ROX $\left(0.40 \mu \mathrm{g} \mathrm{mL} \mathrm{L}^{-1}\right)$.

When comparing the outputs of direct SWV and SW-AdSV methods, the LOQ of the adsorptive method is lower by ca. 5, 40, and 15 times for AZI, CLA, and ROX, respectively. The obtained results indicate that the most sensitive SW-AdSV method was obtained for CLA, but in all cases the protonated macrolides supported adsorptive measurements, significantly increasing the sensitivity of the developed methods.

\subsection{Voltammetric determination of roxithromycin in pharmaceutical preparation}

Using the optimized SW-AdSV method and the $\mathrm{Hg}(\mathrm{Ag}) \mathrm{FE}$, ROX was determined in an appropriately prepared solution of the commercial formulation Runac ${ }^{\circledR}$ with $\mathrm{pH} 7.0$ (Fig. 8). After recording of baseline (curve 1) and voltammogram of commercial formulation with nominal concentration of ROX $0.3 \mu \mathrm{g} \mathrm{mL}^{-1}$ (based on the declaration of the manufacturer, curve 2), three consecutive standard additions were performed (curves 3-5), so that the ROX concentration in voltammetric vessel, thanks to the standard solution, was in the range of $0.10-0.30 \mu \mathrm{g} \mathrm{mL}^{-1}$, which resulted in the found amount of $0.297 \mu \mathrm{g} \mathrm{mL}^{-1}$ of ROX (Fig. 8. inset). The content of ROX in the tablet based on three repeated measurements was 148.8; 150.3 and $149.3 \mathrm{mg}$ per tablet.

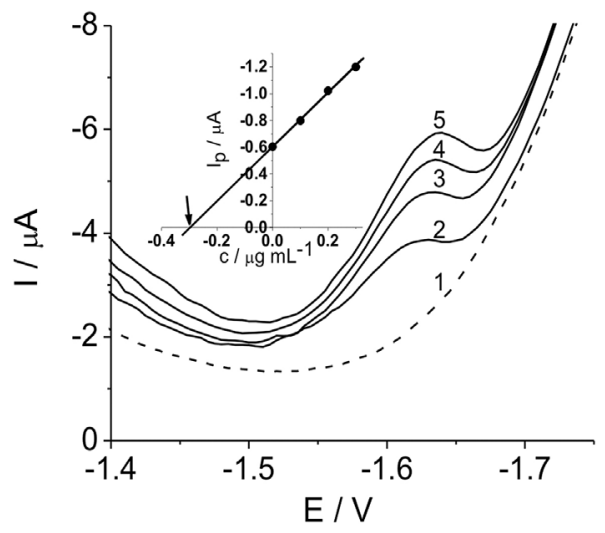

Fig. 8. Determination of the concentration of roxithromycin in the pharmaceutical preparation Runac ${ }^{\mathbb{B}}$ by means of the standard addition method. SW-AdSV s of baseline (1), sample of Runac ${ }^{\mathbb{R}}$ (2), three standard addition of roxithromycin (3-5, with their final concentrations in the voltammetric vessel: $0.10 ; 0.20$ and $0.30 \mu \mathrm{g} \mathrm{mL}^{-1}$ ). $\mathrm{E}_{\mathrm{acc}}-1.05 \mathrm{~V}$ and $\mathrm{t}_{\mathrm{acc}} 15 \mathrm{~s}$. Inset: appropriate analytical curve.

The average content of ROX in the tablet form (Runac ${ }^{\circledR}$ ), obtained by determination of ROX by SW-AdSV method was $149.5 \mathrm{mg}$ per tablet which is in good agreement with the declared content $(150 \mathrm{mg} /$ tablet). The reproducibility of the analytical signal, expressed as the RSD, was $0.5 \%$. Having in mind the basic requirement of European Pharmacopoeia in terms of errors in the accuracy of the measurements, the developed analytical method fulfilled these criteria, and confirmed that in the analyzed tablet the declared amount of ROX was found.

Further investigations are planned concerning of the broadening of application area of the developed $\mathrm{Hg}(\mathrm{Ag}) \mathrm{FE}$ based method, especially the SW-AdSV for the trace level determination of 
different physiologically important compounds with amino functional group(s) and different electroactive centres because in some cases the protonated form of the molecules thanks to their ammonium group(s) could have enhanced adsorption affinity to the appropriately polarized $\mathrm{Hg}(\mathrm{Ag}) \mathrm{FE}$ surface allowing the trace level determination of target compound(s). Additionally, the applicability of the elaborated SW-AdSV methods for CLA, ROX and AZI can be tested for their trace level determination in samples of different origin as samples of human and veterinary medicine, waste-samples of environmental importance and various foodstuffs.

\section{Conclusions}

In the presented work, SWV and SW-AdSV methods were applied in conjunction with the renewable silver-amalgam film electrode $(\mathrm{Hg}(\mathrm{Ag}) \mathrm{FE})$ for characterization and determination of three macrolide antibiotics - azithromycin (AZI), clarithromycin (CLA) and roxithromycin (ROX) in a Britton-Robinson buffer as the supporting electrolyte, with a $\mathrm{pH}$ ranging from 4.0 to 11.9. The reduction peaks recorded for all investigated macrolides were in the potential range between -1.5 and $-1.9 \mathrm{~V}$ vs SCE in a wider $\mathrm{pH}$ range depending on the basic behavior of their electroactive centers. With analytical peak symmetry and intensity $\left(\mathrm{I}_{\mathrm{p}}\right)$ as the criteria, the $\mathrm{pH}$ values selected as optimal for the determination of target analytes were 7.2, 7.4, and 7.0 for AZI, CLA, and ROX, respectively. Based on water-suppressed ${ }^{1} \mathrm{H}$ NMR measurements in the Britton-Robinson buffered media with a pH between 6.0 and 10.5 , it can be concluded that at the optimal $\mathrm{pH}$ values the target analytes are present predominantly in their protonated form via their tertiary amino group. Furthermore, the appropriately polarized $\mathrm{Hg}(\mathrm{Ag}) \mathrm{FE}$ electrode favored the adsorption of target analytes in the positive ionic form.

When the optimized direct SWV method was applied, linear correlations between the concentration of the target analytes and the $I_{p}$ values were obtained for all three macrolides in the concentration ranges of $4.81-23.3 \mu \mathrm{g} \mathrm{mL}^{-1}, 1.96-28.6 \mu \mathrm{g} \mathrm{mL}^{-1}$, and $1.48-25.9 \mu \mathrm{g} \mathrm{mL}^{-1}$ in the case of AZI, CLA, and ROX, respectively. The relative standard deviation (RSD) was lower than $5 \%$ in all cases. After the optimization of the accumulation potential and accumulation time for all three macrolides, the applied SW-AdSV methods exhibited linear $I_{p}$ responses in concentration ranges lower than in the case of $S W V$, with the following respective values for AZI, CLA and ROX: $1.0-2.46 \mu \mathrm{g}$ $\mathrm{mL}^{-1}, 0.05-0.99 \mu \mathrm{g} \mathrm{mL}^{-1}$ and $0.10-0.99 \mu \mathrm{g} \mathrm{mL}^{-1}$. The RSD of the analytical signals was lower than $1.0 \%$ in all investigated cases. Developed SW-AdSV method was applied for determination of ROX in the pharmaceutical preparation Runac ${ }^{\circledR}$ and the obtained average content of ROX ( $149.5 \mathrm{mg} /$ tablet, with RSD of $0.5 \%$ ) is in good agreement with declared content which is $150 \mathrm{mg} /$ tablet.

For the three investigated macrolide antibiotics, the protonated form of the tertiary amino group(s) at the appropriate accumulation potential and time supported the adsorption of target molecules on the $\mathrm{Hg}(\mathrm{Ag}) \mathrm{FE}$ surface, allowing highly sensitive SW-AdSV methods of their trace level analysis, especially in the case of CLA and ROX. These findings are consistent with our recent paper concerning the application of an $\mathrm{Hg}(\mathrm{Ag}) \mathrm{FE}$-based SW-AdSV method for the determination of another amino functional group containing electroactive macrolide antibiotic derivative - erythromycin ethylsuccinate [35].

\section{Acknowledgements}

The authors acknowledge the financial support of the Ministry of Science and Technological Development of the Republic of
Serbia (Project No. 172012 and 172013) and CEEPUSIII (CZ-021209-1516) network.

\section{Appendix A. Supplementary data}

Supplementary data associated with this article can be found, in the online version, at http://dx.doi.org/10.1016/j.electacta.2017. 01.146 .

\section{References}

[1] S. Omura, H. Tanaka, in: S. Omura (Ed.), Macrolide Antibiotics: Chemistry, Biology, and Practice, Academic Press, Orlando, 1984 p. 3.

[2] M.J. González de la Huebra, G. Bordin, A.R. Rodríguez, A multiresidue method for the simultaneous determination of ten macrolide antibiotics in human urine based on gradient elution liquid chromatography coupled to coulometric detection (HPLC-ECD), Anal. Chim. Acta 517 (2004) 53.

[3] F. Kees, S. Spangler, M. Wellenhofer, Determination of macrolides in biological matrices by high-performance liquid chromatography with electrochemical detection, J. Chromatogr. A 812 (1998) 287.

[4] K. -Yu Chen, T.C. Yang, S.Y. Chang, Determination of macrolide antibiotics using dispersive liquid-liquid microextraction followed by surface-assisted laser desorption/ionization mass spectrometry, J. Am. Soc. Mass Spectrom 23 (2012) 1157.

[5] M.S. Whitman, A.R. Tunkel, Azithromycin and clarithromycin: overview and comparison with erythromycin, Infect. Control Hosp. Epidemiol. 13 (1992) 357.

[6] M.J. González de la Huebra, U. Vincent, Analysis of macrolide antibiotics by liquid chromatography, J. Pharm. Biomed. Anal. 39 (2005) 376.

[7] J.M. Zuckerman, Macrolides and ketolides: azithromycin, clarithromycin, telithromycin, Infect. Dis. Clin. N. Am. 18 (2004) 621.

[8] Z. Wang, J. Wang, M. Zhang, L. Dang, Solubility of erythromycin A dihydrate in different pure solvents and acetone + water binary mixtures between $293 \mathrm{~K}$ and 323 K, J. Chem. Eng. Data 51 (2006) 1062.

[9] The United States Pharmacopoeia, 25th rev., Easton, Rand McNally, Taunton, MA, 2002, Fourth Supplement, p.189.

[10] I. Kanfer, M.F. Skinner, R.B. Walker, Analysis of macrolide antibiotics, J. Chromatogr. A 812 (1998) 255.

[11] A. Bryskier, Roxithromycin: Review of its antimicrobial activity, J. Antimicrob. Chemother. 41 (Suppl. B) (1998) 1.

[12] M. Menzel, H. Akbarshahi, L. Bjermer, L. Uller, Azithromycin induces anti-viral effects in cultured bronchial epithelial cells from COPD patients, Sci. Rep. 6 (2016) 1.

[13] M.G. Sturgill, R.P. Rapp, Clarithromycin: review of a new macrolide antibiotic with improved microbiologic spectrum and favorable pharmacokinetic and adverse effect profiles, Ann. Pharmacother. 26 (1992) 1099.

[14] H. Lode, K. Borner, P. Koeppe, T. Schaberg, Azithromycin-review of key chemical, pharmacokinetic and microbiological features, J. Antimicrobial. Chemother. 37 (Suppl. C) (1996) 1.

[15] S.C. Piscitelli, L.H. Danziger, K.A. Rodvold, Clarithromycin and azithromycin: new macrolide antibiotics, Clin. Pharm. 11 (1992) 137.

[16] B. Yu, X. Wang, S. Yu, Q. Li, Q. Zhou, Effects of roxithromycin on ammoniaoxidizing bacteria and nitrite-oxidizing bacteria in the rhizosphere of wheat, Appl. Microbiol. Biotechnol. 98 (2014) 263.

[17] M.L. Qi, P. Wang, R.H. Cong, J.J. Yang, Simultaneous determination of roxithromycin and ambroxol hydrochloride in a new tablet formulation by liquid chromatography, J. Pharm. Biomed. Anal. 35 (2004) 1287.

[18] H. Lassman, S. Puri, I. Ho, R. Sabo, M. Mezzino, Pharmacokinetics of roxithromycin, J. Clin. Parmacol. 28 (1988) 141.

[19] H. Kirst, G. Sides, New directions for macrolide antibiotics: Pharmacokinetics and clinical efficacy, Antimicrob. Agents. Chemother. 33 (1989) 1419.

[20] J.D. Williams, A.M. Sefton, Comparison of macrolide antibiotics, J. Antimicrob. Chemother. 31 (Suppl. C) (1993) 11.

[21] L.K. Bekele, G.G. Gebeyehu, Application of different analytical techniques and microbiological assays for the analysis of macrolide antibiotics from pharmaceutical dosage forms and biologicalmatrices, ISRN Anal. Chem. 2012 (2012) 1.

[22] S. Jia, J. Li, S.-R. Park, Y. Ryu, I.H. Park, J.H. Park, S.-S. Hong, S.W. Kwon, J. Lee, Combined application of dispersive liquid? liquid microextraction based on the solidification of floating organic droplets and charged aerosol detection for the simple and sensitive quantification of macrolide antibiotics in human urine, J. Pharm. Biomed. Anal. 86 (2013) 204.

[23] R.P. da Costa, B.F. Spisso, M.U. Pereira, M.A. Monteiro, R.G. Ferreira, A.W. da Nóbrega, Innovative mixture of salts in the quick, easy, cheap, effective, rugged, and safe method for the extraction of residual macrolides in milk followed by analysis with liquid chromatography and tandem mass spectrometry, J. Sep. Sci. 38 (2015) 3743.

[24] W. Li, H. Jia, K. Zhao, Determination of clarithromycin in rat plasma by HPLCUV method with pre-column derivatization. Talanta 71 (2007) 385.

[25] European Pharmacopoeia, 5h ed., Council of Europe, Vol. 2(2005) pp. 1039, 1309, 2379.

[26] O.A.E.-M. Farghaly, N.A.L. Mohamed, Voltammetric determination of azithromycin at the carbon paste electrode, Talanta 62 (2004) 531. 
[27] B. Nigović, B. Šimunić, Voltammetric assay of azithromycin in pharmaceutical dosage forms, J. Pharm. Biomed. Anal. 32 (2003) 197.

[28] M.L. Avramov-Ivić, S.D. Petrović, D.Ž. Mijin, A study of the electrochemical activity of some macrolide antibiotics on a gold electrode in a neutral electrolyte, J. Serb. Chem. Soc. 72 (2007) 1427.

[29] K.M. Drljević-Djurić, V.D. Jović, U.Č. Lacnjevac, M.L. Avramov-Ivić, S.D. Petrović, D.Ž. Mijin, S.B. Djordjević, Voltammetric and differential pulse determination of roxithromycin, Electrochim. Acta 56 (2010) 47.

[30] L. Zhang, X. Duan, Y. Wen, J. Xu, Y. Yao, Y. Lu, L. Lu, O. Zhang, Electrochemical behaviors of roxithromycin at poly(3,4-ethylenedioxythiophene) modified gold electrode and its electrochemical determination, Electrochim. Acta 72 (2012) 179.

[31] H. Wan, F. Zhao, W. Wu, B. Zeng, Direct electron transfer and voltammetric determination of roxithromycin at a single-wall carbon nanotube coated glassy carbon electrode, Colloids Surf. B: Biointerfaces 82 (2011) 427.

[32] J. Wang, J.S. Mahmoud, Determination of traces of streptomycin and related antibiotics by adsorptive stripping voltammetry, Anal. Chim. Acta 186 (1986) 31.

[33] Z. Zhang, H. Tuo, On the linear scanning polarographic method of erythromycin ethylsuccinate, Journal of Yanan University (Natural Science Edition) 26 (2007) 1.

[34] M.M. Ghoneim, M.A. El-Attar, Adsorptive stripping voltammetric determination of antibiotic drug clarithromycin in bulk form, pharmaceutical formulation and human urine, Chemical Analysis/Chemia Analityczna 53 (2008) 689.

[35] O. Vajdle, V. Guzsvány, D. Škorić, J. Anojčić, P. Jovanov, M. Avramov-Ivić, J. Csanádi, Z. Kónya, S. Petrović, A. Bobrowski, Voltammetric behavior of erythromycin ethylsuccinate at a renewable silver-amalgam film electrode and its determination in urine and in a pharmaceutical preparation, Electrochim. Acta 191 (2016) 44.

[36] Ø. Mikkelsen, K.H. Schrøder, Amalgam electrodes for electroanalysis, Electroanal. 15 (2003) 679.

[37] K. Nováková, V. Hrdlička, T. Navrátil, V. Vyskočil, J. Barek, Determination of 5nitroindazole using silver solid amalgam electrode, Monatsh. Chem. 146 (2015) 761.

[38] A. Danhel, K. Keung Shiu, B. Yosypchuk, J. Barek, K. Peckova, V. Vyskocil, The use of silver solid amalgam working electrode for determination of nitrophenols by HPLC with electrochemical detection, Electroanal. 21 (2009) 303.

[39] A. Bobrowski, A. Królicka, R. Bobrowski, Renewable silver amalgam film electrodes in electrochemical stripping analysis-a review, J. Solid. State Electrochem. 20 (2016) 1.

[40] A. Danhel, J. Barek, Amalgam electrodes in organic electrochemistry, Curr. Org. Chem. 15 (2011) 2957.

[41] O. Vajdle, J. Zbiljić, B. Tasić, D. Jović, V. Guzsvány, A. Djordjevic, Voltammetric behavior of doxorubicin at a renewable silver-amalgam film electrode and its determination in human urine, Electrochim. Acta 132 (2014) 49.

[42] M. Brycht, A. Nosal-Wiercińska, K. Sipa, K. Rudnicki, S. Skrzypek, Electrochemical determination of closantel in the commercial formulation by square-wave adsorptive stripping voltammetry, Monatsh. Chem. (2016), doi:http://dx.doi.org/10.1007/s00706-016-1862-z Article in press.

[43] S. Skrzypek, Electrochemical study of moroxydine and its voltammetric determination with a silver amalgam film electrode, Electroanal. 23 (2011) 2781.

[44] S. Smarzewska, D. Guziejewski, M. Skowron, S. Skrzypek, W. Ciesielski, Voltammetric behavior and quantitative determination of ambazone concentrations in urine and in a pharmaceutical formulation, Cent. Eur. J. Chem. 12 (2014) 1239.

[45] S. Smarzewska, S. Skrzypek, W. Ciesielski, Voltammetric determination of proguanil in malarone and spiked urine with a renewable silver amalgam film electrode, Electroanal. 24 (2012) 1966.

[46] J. Smajdor, R. Piech, B. Paczosa-Bator, A novel method of high sensitive determination of prednisolone on renewable mercury film silver based electrode, Electroanal. 28 (2016) 394.

[47] V. Guzsvány, J. Petrović, J. Krstić, Zs. Papp, M. Putek, L. Bjelica, A. Bobrowski, B. Abramović, Renewable silver-amalgam film electrode for voltammetric monitoring of solar photodegradation of imidacloprid in the presence of $\mathrm{Fe} /$ $\mathrm{TiO}_{2}$ and $\mathrm{TiO}_{2}$ catalysts, J. Electroanal. Chem. 699 (2013) 33.

[48] M. Putek, V. Guzsvány, B. Tasić, Zs. Papp, J. Zarębski, A. Bobrowski, Renewable silver-amalgam film electrode for rapid square-wave voltammetric determination of thiamethoxam insecticide in selected samples, Electroanal. 24 (2012) 2258.

[49] M. Brycht, O. Vajdle, J. Zbiljić, Zs. Papp, V. Guzsvány, S. Skrzypek, Renewable silver-amalgam film electrode for direct cathodic SWV determination of clothianidin, nitenpyram and thiacloprid neonicotinoid insecticides reducible in a fairly negative potential range, Int. J. Electrochem. Sc. 7 (2012) 10652.
[50] M. Brycht, S. Skrzypek, V. Guzsvány, J. Berenji, Conditioning of renewable silver amalgam film electrode for the characterization of clothianidin and its determination in selected samples by adsorptive square-wave voltammetry, Talanta 117 (2013) 242.

[51] S. Smarzewska, S. Skrzypek, W. Ciesielski, Renewable silver amalgam film electrode for the determination of dinotefuran in spiked carrot juice samples using SW voltammetry, Electroanal. 24 (2012) 1591.

[52] D. Guziejewski, S. Smarzewska, M. Skowron, W. Ciesielski, A. NosalWiercinłska, S. Skrzypek, Rapid and sensitive voltammetric determination of aclonifen in water samples, Acta Chim. Slov. 63 (2016) 1.

[53] M. Brycht, S. Skrzypek, J. Robak, V. Guzsvány, O. Vajdle, J. Zbiljić, A. NosalWiercińska, D. Guziejewski, G. Andrijewski, Ultra trace level determination of fenoxanil by highly sensitive square-wave adsorptive stripping voltammetry in real samples with a renewable silver amalgam film electrode, J. Electroanal. Chem. 738 (2015) 69.

[54] M. Brycht, B. Burnat, A. Nosal-Wiercińska, S. Skrzypek, New sensitive squarewave adsorptive stripping voltammetric determination of pesticide chlornitrofen, and an evaluation of its corrosivity towards steel agricultural equipment, J. Electroanal. Chem. 777 (2016) 8.

[55] Z. Mandić, Z. Weitner, M. Ilijaš, Electrochemical oxidation of azithromycin and its derivatives, J. Pharm. Biomed. Anal. 33 (2003) 647.

[56] J. Feitosa-Felizzola, S. Chiron, Occurrence and distribution of selected antibiotics in a small Mediterranean stream (Arc River Southern France), J. Hydrol. 364 (2009) 50.

[57] Z. Mandić, Voltammetric study of the partitioning of macrolide antibiotics at the water/nitrobenzene interface. Relationship to the pharmacokinetic profiling of macrolides, ADMET \& DMPK 2 (2014) 168.

[58] R. Yanamandra, A. Chaudhary, S. Rao Bandar, B. Patro, Y.L.N. Murthy, P.A. Ramaiah, C.S.P. Sastry, UPLC method for simultaneous separation and estimation of secnidazole, fluconazole and azithromycin in pharmaceutical dosage forms, E-J. Chem. 7 (2010) S363.

[59] J.W. McFarland, C.M. Berger, S.A. Froshauer, S.F. Hayashi, S.J. Hecker, B.H. Jaynes, M.R. Jefson, B.J. Kamicker, C.A. Lipinski, K.M. Lundy, C.P. Reese, C.B. Vu, Quantitative structure-activity relationships among macrolide antibacterial agents: In vitro and in vivo potency against pasteurellamultocid, J. Med. Chem. 40 (1997) 1340

[60] Tuberculosis 88 (2008) 92.

[61] T.J. Ives, E.L. Marston, R.L. Regnery, J.D. Butts, T.C. Majerus, In vitro susceptibilities of Rickettsia and Bartonella spp. to 14-hydroxyclarithromycin as determined by immunofluorescent antibody analysis of infected Vero cell monolayers, J. Antimicrob. Chemother. 45 (2000) 305.

[62] Y. Nakagawa, S. Itai, T. Yoshida, T. Nagai, Physicochemical properties and stability in the acidic solution of a new macrolide antibiotic, clarithromycin, in comparison with erythromycin, Chem. Pharm. Bull. 40 (1992) 725.

[63] K. Togami, S. Chono, T. Seki, K. Morimoto, Distribution characteristics of telithromycin, a novel ketolide antimicrobial agent applied for treatment of respiratory infection, in lung epithelial lining fluid and alveolar macrophages, Drug Metab. Pharmacokinet. 24 (2009) 411.

[64] J. Gharbi-Benarous, P. Ladam, M. Delaforge, J.-P. Girault, Conformationa analysis of major metabolites of macrolide antibiotics roxithromycin and erythromycin A with different biological properties by NMR spectroscopy and molecular dynamics, J. Chem. Soc. Perkin Trans. 2 (1993) 2303.

[65] F. Kees, A. Holstege, K.P. Ittner, M. Zimmermann, G. Lock, J. Schölmerich, H. Grobecker, Pharmacokinetic interaction between proton pump inhibitors and roxithromycin in volunteers, Aliment. Pharmacol. Ther. 14 (2000) 407.

[66] S. Suárez, M. Carballa, F. Omil, J.M. Lema, How are pharmaceutical and persona care products (PPCPs) removed from urban wastewaters? Rev. Environ. Sci. Biotechnol. 7 (2008) 125.

[67] M.-V. Salvia, J. Experton, C. Geandel, C. Cren-Olivé, E. Vulliet, Fate of pharmaceutical compounds and steroid hormones in soil: study of transfer and degradation in soil columns, Environ. Sci. Pollut. Res. 21 (2014) 10525.

[68] M. Zrnčić, S. Babić, D. Mutavdžić Pavlović, Determination of thermodynamic $\mathrm{pK}_{\mathrm{a}}$ values of pharmaceuticals from five different groups using capillary electrophoresis, J. Sep. Sci. 38 (2015) 1232.

[69] B. Baś, Refreshable mercury film silver based electrode for determination of chromium(VI) using catalytic adsorptive stripping voltammetry, Anal. Chim. Acta 570 (2006) 195.

[70] V. Guzsvány, J. Csanádi, F. Gaál, NMR study of the influence of pH on the persistence of some neonicotinoids in water, Acta Chim. Slov. 53 (2006) 52.

[71] K.P.C. Vollhardt, N.E. Schore, Organic Chemistry, W.H., Freeman and Company, New York and Oxford, 1994.

[72] S. Yagmur, S. Yilmaz, G. Saglikoglu, M. Sadikoglu, M. Yildiz, K. Polat, Synthesis, spectroscopic studies and electrochemical properties of Schiff bases derived from 2-hydroxy aromatic aldehydes and phenazopyridine hydrochloride, J. Serb. Chem. Soc. 78 (2013) 795.

[73] D.K. Gosser, Cyclic voltammetry, VCH, New York, 1994. 